\title{
Congenital pulmonary vein stenosis at an African tertiary care centre over a 25-year period
}

Mamaila Lebea*,\#, Antoinette M. Cilliers",t and Hopewell N. Ntsinjana*,\#

\section{*Department of Paediatrics and Child Health, Paediatric Cardiology Division, University of the Witwatersrand, Johannesburg, South Africa \\ \#Department of Paediatrics and Child Health, Paediatric Cardiology Division, Nelson Mandela Childrens Hospital, Johannesburg, South Africa \\ tDepartment of Paediatrics and Child Health, Paediatric Cardiology Division, Baragwanath Academic Hospital, Johannesburg, South Africa}

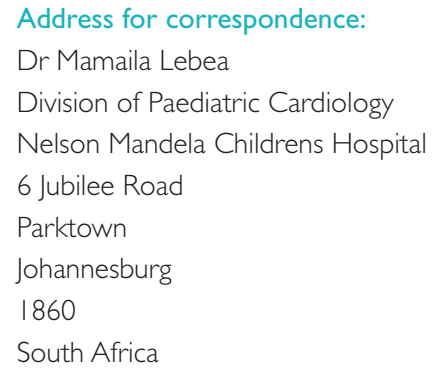

Mamaila.lebea@nmch.org.za or lbxmam00।@yahoo.com

\section{INTRODUCTION}

Congenital pulmonary vein stenosis (PVS) is a rare condition, resulting from abnormal incorporation of the common pulmonary vein into the left atrium. (1-3) $^{-}$One or more of the 4 pulmonary veins may be involved and it is commonly associated with other congenital heart defects (CHD), but can occur in isolation. (2-4) Commonly, patients present with respiratory symptoms with varying degrees of pulmonary hypertension. ${ }^{(5,6)}$ Surgical results are generally poor with a high risk of recurrence and high mortality. ${ }^{(3)}$ Reports are limited to small case series with little data on outcomes. (7) The aim of the study was to describe a series of cases with congenital pulmonary vein stenosis seen at the Chris Hani Baragwanath Academic Hospital, a large Southern African tertiary institution, over a 25-year period.

\section{METHODS AND SUBJECTS}

Patients were retrospectively identified using an electronic paediatric cardiology database system dating from January 1990

\section{ABSTRACT}

Background: Congenital pulmonary vein stenosis (PVS) is a rare condition, which results from abnormal embryological incorporation of the common pulmonary vein into the left atrium.

Methods: A retrospective descriptive case series study was conducted with the aim of describing the characteristics and outcome of children with congenital PVS at an African tertiary care centre over a 25-year period. A computerised paediatric cardiology database initiated in the early 1990s was sourced to identify patients, following which clinical records were retrieved and reviewed.

Results: Five cases of congenital PVS were identified between January 1990 and January 2016 and accounted for $\mathbf{0 . 0 0 0 7 \%}$ of all congenital heart defects seen at the centre during the study period. The age at diagnosis ranged from 22 months - 13 years. Most patients presented with respiratory symptoms, with 2 patients presenting with recurrent haemoptysis. The diagnosis of PVS was confirmed by cardiac catheterisation and pulmonary angiography in all patients. All cases were right-sided unilateral PVS and all were associated with one or more congenital heart defects. Mild pulmonary hypertension and elevated capillary wedge pressures were found in all patients. Only one patient underwent specific surgery to relieve the PVS, which subsequently recurred. Another patient underwent a lobectomy following recurrent haemoptysis, but subsequently died of sepsis.

Conclusion: Congenital PVS is a rare condition often associated with other congenital cardiac defects. Respiratory symptoms are common at presentation, with haemoptysis forming part of the presenting clinical spectrum, which is in keeping with the published literature. Elevated pulmonary artery pressures and increased ipsilateral pulmonary capillary wedge pressures are a common finding at catheterisation.

SAHeart 2019;16:318-323

to January 20 I5. Clinical notes, catheterisation and imaging data of patients were reviewed. Data extracted for analysis included patient demographics, site of the lesion and the number of veins affected, associated congenital heart defects (CHD), and management strategies and outcomes. Patients with anomalous venous connection were excluded from this analysis. 


\section{RESULTS}

Five patients with congenital PVS were identified; congenital PVS accounted for $0.0007 \%$ of all CHD (5 out of 7345 cases) seen at our institution during the same time period. Three of the 5 patients were females and the age at diagnosis ranged from 22 months - 13 years. All cases of PVS were unilateral and right-sided and were associated with other CHD (Table I).

Four of the 5 patients presented with respiratory distress, with one patient diagnosed incidentally during cardiac catheterisation undertaken to investigate the cause of pulmonary hypertension. The other presenting symptom was haemoptysis in 2 of the 5 patients. All the patients had invasive cardiac catheterisation, which assisted in the diagnosis or confirmation of PVS. All were found to have pulmonary hypertension with mean pulmonary artery pressure (PAP) exceeding $25 \mathrm{mmHg}$ and all were also noted to have elevated pulmonary artery wedge pressures on the ipsilateral side of the PVS (Table 2). Of note, there was no elevation of oxygen saturations in the affected ipsilateral pulmonary artery, which can be associated with PVS as outlined in the discussion below. As part of management, all the patients underwent corrective surgery for the associated CHD.

Case I was referred for cardiac assessment at the age of 10 months when she presented with shortness of breath and was noted to have a cardiac murmur. She underwent cardiac catheterisation for assessment of VSD and was found to have right upper and lower PVS. She had surgical closure of the VSD and widening of the pulmonary veins using a pericardial patch at the age of 12 months. She remained asymptomatic following the surgery but presented at the age of 10 years with respiratory distress and chest pain. She was found to have a double chamber right ventricle (DCRV), severe tricuspid regurgitation and recurrence of the PVS. She had surgery for resection of a right ventricle muscle bundle and repair of the tricuspid valve at the age of 12 years, with no further surgery on the pulmonary veins. At the age of 25 years, she remains asymptomatic in relation to the PVS.

Case 2 presented with respiratory distress and recurrent haemoptysis, and multimodality imaging with CT (Figure IA and IB) and an $\mathrm{X}$-ray pulmonary angiogram confirmed a diagnosis of right upper and lower PVS. Her associated CHD were a PDA and a discrete subaortic stenosis (DSAS), which were surgically managed. She underwent a right lower lobe lobectomy at the age of 22 months for a life threatening haemoptysis, but died a few days later from K. pneumoniae sepsis. The histology of the right lower lobe showed fresh alveolar haemorrhage and patchy oedema, with accumulation of intraparenchymal siderophages and a chronic inflammatory cell infiltrate. A small vessel resembling the pulmonary vein was identified, which had mild thickening of the media, thickened adventitial collagen and focal arterialisation. The pulmonary artery appeared abnormal with expansion of the intima by

TABLE I: Patient characteristics.

\begin{tabular}{|c|c|c|c|c|c|c|c|c|}
\hline Case & $\begin{array}{l}\text { Age at } \\
\text { diagnosis }\end{array}$ & Sex & $\begin{array}{l}\text { No. of } \\
\text { veins } \\
\text { affected }\end{array}$ & Side & Presentation & $\begin{array}{c}\text { Other cardiac } \\
\text { anomaly }\end{array}$ & Surgery & Outcome \\
\hline । & 10 months & $\mathrm{F}$ & 2 & $\mathrm{R}$ & Shortness of breath & $\begin{array}{l}\text { VSD, DCRV } \\
\text { Severe TR }\end{array}$ & $\begin{array}{l}\text { VSD closure } \\
\text { RV muscle bundle } \\
\text { resection } \\
\text { TV repair } \\
\text { Widening of the } \\
\text { pulmonary vein orifice }\end{array}$ & Recurrence of PVS \\
\hline 2 & 22 months & $\mathrm{F}$ & 2 & $\mathrm{R}$ & $\begin{array}{c}\text { Shortness of breath, } \\
\text { haemoptysis }\end{array}$ & PDA, DSAS & $\begin{array}{l}\text { PDA ligation, } \\
\text { DSAS Resection } \\
\text { Lobectomy }\end{array}$ & Died \\
\hline 3 & 6 years & M & I & $\mathrm{R}$ & $\begin{array}{l}\text { Recurrent chest } \\
\text { infections }\end{array}$ & VSD, DSAS & $\begin{array}{l}\text { VSD closure and } \\
\text { DSAS resection }\end{array}$ & Lost to FU \\
\hline 4 & 10 years & M & । & $\mathrm{R}$ & $\begin{array}{l}\text { Pulmonary } \\
\text { hypertension }\end{array}$ & TGV & Atrial switch & Lost to FU \\
\hline 5 & 13 years & $\mathrm{F}$ & 2 & $\mathrm{R}$ & $\begin{array}{c}\text { Haemoptysis, } \\
\text { shortness of breath }\end{array}$ & $\begin{array}{l}\text { ASD, } \\
\text { Cor triatriatum }\end{array}$ & $\begin{array}{l}\text { ASD closure and } \\
\text { resection of } \\
\text { Cor triatriatum }\end{array}$ & $\begin{array}{l}\text { Intermittent minor } \\
\text { haemoptysis }\end{array}$ \\
\hline
\end{tabular}

$A S D=$ trial septal defect, DSAS = discrete subaortic stenosis, $D C R V=$ double chamber right ventricle, $F=$ female, FU $=$ follow- $u p, M=$ male, $P D A=$ patent ductus arteriosus, $R=$ right, VSD = ventricular septal defect, $T B=$ tuberculosis, $T G V=$ transposition of great vessels, $T R=$ tricuspid regurgitation, $T V=$ tricuspid valve. 
TABLE II: Haemodynamic data in patients with pulmonary vein stenosis.

\begin{tabular}{|c|c|c|c|c|c|}
\hline $\begin{array}{c}\text { Site } \\
\text { Pressures } \\
\text { (mmHg) } \\
\text { Saturation } \\
(\%)\end{array}$ & Case I & Case 2 & Case 3 & Case 4 & Case 5 \\
\hline $\mathrm{RV}$ & $\begin{array}{c}41 / 0 / 6 \\
82 \%\end{array}$ & $62 / 0 / 10$ & $\begin{array}{c}49 / 0 / 4 \\
70 \%\end{array}$ & $\begin{array}{c}38 / 0 / 4 \\
72 \%\end{array}$ & $\begin{array}{c}40 / 0 / 15 \\
80 \%\end{array}$ \\
\hline MPA & $40 / 20 / 27$ & $38 / 15 / 33$ & $\begin{array}{c}49 / 11 / 29 \\
77 \%\end{array}$ & $\begin{array}{c}40 / 13 / 28 \\
74 \%\end{array}$ & $\begin{array}{c}38 / 20 / 29 \\
74 \%\end{array}$ \\
\hline RPA & $\begin{array}{c}4 \mid / 14 / 28 \\
88 \%\end{array}$ & $37 / 11 / 23$ & $\begin{array}{c}45 / 10 / 28 \\
77 \%\end{array}$ & $\begin{array}{c}36 / 15 / 25 \\
74 \%\end{array}$ & $\begin{array}{c}42 / 20 / 28 \\
76 \%\end{array}$ \\
\hline LPA & $35 / 17 / 26$ & $32 / 11 / 21$ & $\begin{array}{c}49 / 12 / 30 \\
77 \%\end{array}$ & $\begin{array}{c}37 / 14 / 25 \\
74 \%\end{array}$ & $\begin{array}{c}42 / 18 / 28 \\
75 \%\end{array}$ \\
\hline RPW & $M=22$ & $M=11$ & $M=23$ & $M=40$ & $M=19$ \\
\hline LPW & & $M=14$ & $M=12$ & $M=10$ & $M=15$ \\
\hline LV & $115 / 0 / 12$ & $44 / 0 / 4$ & $\begin{array}{c}94 / 0 / 6 \\
92 \%\end{array}$ & $\begin{array}{c}110 / 0 / 5 \\
91 \%\end{array}$ & $\begin{array}{c}120 / 0 / 15 \\
97 \%\end{array}$ \\
\hline AAO & $\begin{array}{c}66 / 34 / 50 \\
100 \%\end{array}$ & $62 / 31 / 42$ & $\begin{array}{c}92 / 54 / 70 \\
92 \%\end{array}$ & $\begin{array}{c}110 / 78 / 90 \\
91 \%\end{array}$ & $\begin{array}{c}120 / 80 / 100 \\
96 \%\end{array}$ \\
\hline
\end{tabular}

Pressures recorded as systolic/mean/diastolic. $A A O=$ ascending aorta, $L P A=$ left pulmonary artery, $L P W=$ left pulmonary wedge, $L V=l e f t$ ventricle, $M=$ mean, $M P A=$ main pulmonary artery, $R P A=$ right pulmonary artery, $R P W=$ right pulmonary wedge.

myofibroblasts and medial hypertrophy with prominent collagenous adventitia. The arterioles were muscularised. The lymphatic vessels in the centrilobular areas, interlobular septae and pleura were ectatic.

Case 3 was referred for cardiac assessment at the age of 6 years because of recurrent lower respiratory tract infections and a cardiac murmur. He underwent cardiac catheterisation for assessment of a VSD and a DSAS and was found to have right upper PVS. He remained asymptomatic after repair of the associated CHD and was subsequently lost to follow-up at the age of 13 years.

Case 4 was diagnosed with transposition of the great vessels (TGV) and had an atrial switch operation done at another hospital during the neonatal period. He was referred to our institution at 10 years of age for continued follow-up, where he was noted to have pulmonary hypertension on routine echocardiography. Cardiac catheterisation was performed to investigate the cause of the pulmonary hypertension and a pulmonary angiogram showed right upper PVS. This patient was subsequently lost to follow-up one year after the diagnosis of PVS, and was noted to be asymptomatic at the last clinic follow-up date.

Case 5 was diagnosed with cor triatriatum and an atrial septal defect (ASD), which was repaired at 12 months of age. She continued to be followed up post-operatively and presented with recurrent haemoptysis and respiratory distress at 13 years of age. A computerised tomography (CT) angiogram showed PVS, which was confirmed at invasive catheterisation (Figure 2A and $2 \mathrm{~B}$ ). At the age of 24 years, she continues to have recurrent episodes of minor haemoptysis and shortness of breath. She has had a successful pregnancy and has refused a lobectomy of the affected lung.

\section{DISCUSSION}

We were able to identify 5 cases of congenital PVS over 25 years at an African tertiary care centre, confirming the rarity of the condition. ${ }^{(1-3)}$ A review of the literature has identified a small number of publications mostly in the form of case reports and small case series of congenital PVS.(3-7) The largest cohort of patients with congenital PVS published from one centre consisted of 31 patients identified over 20 years, with the incidence of congenital PVS among patients with congenital heart defects of $0.03 \%$ (3। of 98 126). ${ }^{(6)}$

Congenital PVS is thought to result from abnormal incorporation of the common pulmonary vein into the left atrium. ${ }^{(1-3)}$ One or more of the 4 pulmonary veins may be involved, and may be unilateral on the left or right or bilateral and involve either lung. ${ }^{(1-5)}$ All the cases of PVS in our study were unilateral and right sided, and only one or 2 pulmonary veins were 

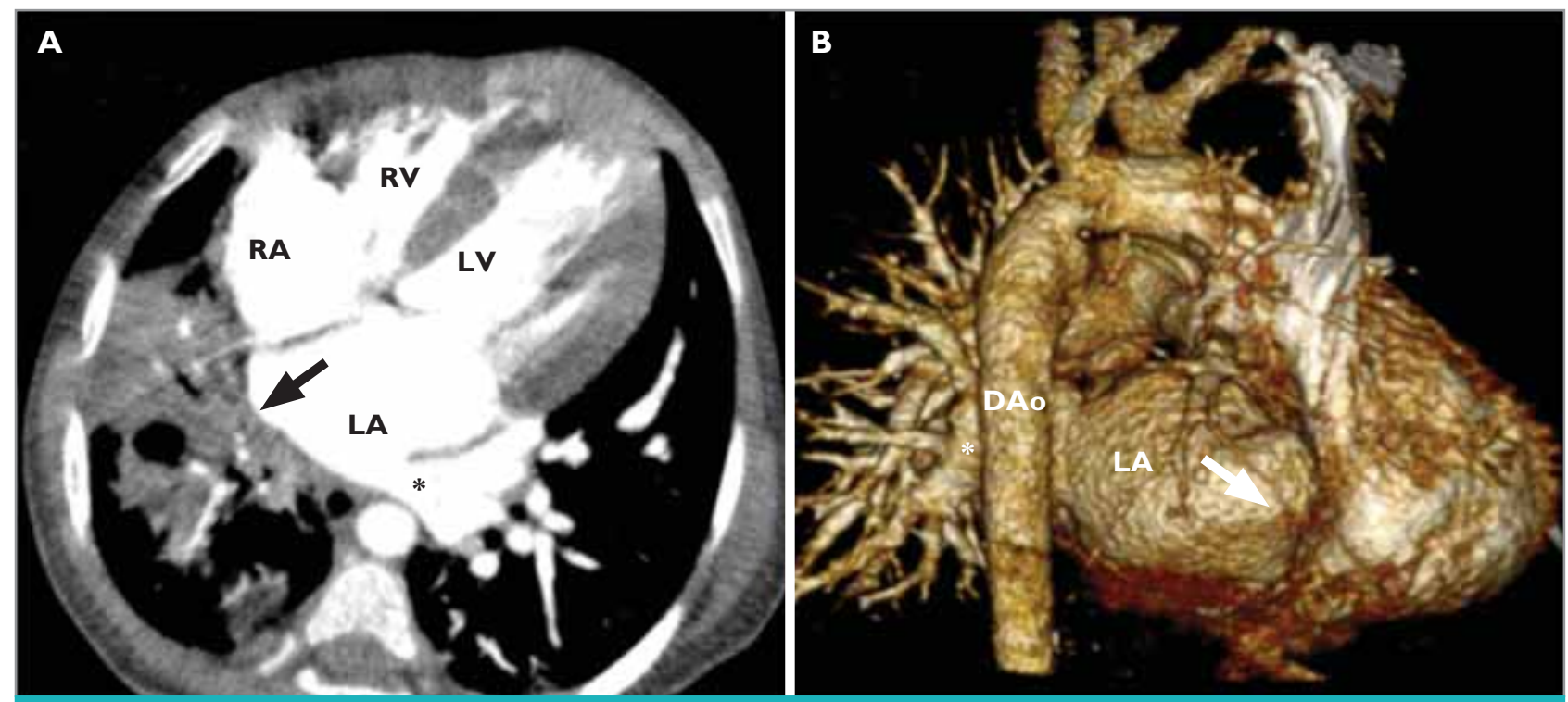

FIGURE IA CT angiogram and FIGURE IB CT reconstruction: From case 2 showing 2 left pulmonary veins connecting to the left atrium (star).

On the right, the pulmonary veins are not seen, with smooth left atrial wall at the expected location of the right pulmonary veins. There are pulmonary parenchymal changes on the right (Figure IB).

$D A o=$ descending aorta, $L A=$ left atrium, $L V=$ left ventricle, $R=$ right, $R A=$ right atrium, $R V=$ right ventricle, $R P A=$ right pulmonary artery, $P V=$ pulmonary vein.

involved. In contrast, Kingston, et al. reported 3 cases of unilateral left-sided PVS at the Royal Manchester Children's Hospital in the United Kingdom. Furthermore, it has been observed that patients with unilateral PVS can progress to bilateral involvement. ${ }^{(6)}$

The clinical presentation of patients in this study is comparable to previously reported case series where patients usually present with recurrent pulmonary symptoms, including haemoptysis. ${ }^{(2-5)}$ The age at diagnosis, however, differed from other case series, with 4 of our patients being diagnosed at a relatively older age, after 3 years. Most patients with congenital PVS are documented to present in the first few months to years of life. (2.5.7) $^{2}$ The timing and severity of symptoms is dependent on the number of pulmonary veins stenosed and the severity of the obstruction in each individual vein, with poor outcomes occurring in those with 3 or 4 pulmonary veins involved. (2,3) Breinholt et al. noted that patients with stenosis of only one or 2 pulmonary veins manifested with symptoms at an older age, ${ }^{(8)}$ which may be the reason for the later presentation and diagnosis in our patients - all of whom had involvement of I - 2 pulmonary veins (Table I). Congenital PVS is caused by a progressive neoproliferative process and may not be present at birth. ${ }^{(2,3)}$ It is also possible that the study patients have a more benign disease process, which progresses more slowly, and hence the late presentation and diagnosis.
The incidence of associated congenital heart defects in patients with congenital PVS ranges from 30\% - 80\%.(2,3) We have reported a higher incidence of associated CHDs with 100\% of our patients having one or more associated CHDs.

All patients were found to have mildly elevated pulmonary artery pressures, associated with markedly increased pulmonary capillary wedge pressures on the affected side (Table 2). The unilateral nature of the disease may explain the mild elevation of pulmonary artery pressures, because the unaffected contralateral side provides a channel for decompression of elevated pulmonary pressures. ${ }^{(3)}$ As a result of decreased pulmonary blood flow on the affected side, the pulmonary artery may become hypoplastic and systemic collateral arteries to that side can develop. ${ }^{(3,6)}$ The systemic collateral arterial flow into the hypoplastic pulmonary artery on the affected side contributes to the raised pulmonary artery wedge pressure, and also to the higher pulmonary artery oxygen saturations reported in some patients with unilateral PVS.(3) Although hypoplastic right pulmonary arteries were present in patients 2 and 5 (Table I), the latter physiological feature was not observed.

PVS is associated with significant morbidity and mortality, with a less than 50\% 5-year survival.(3,7,8) Although the small cohort of 5 patients, and the high level of loss to follow-up limit our 

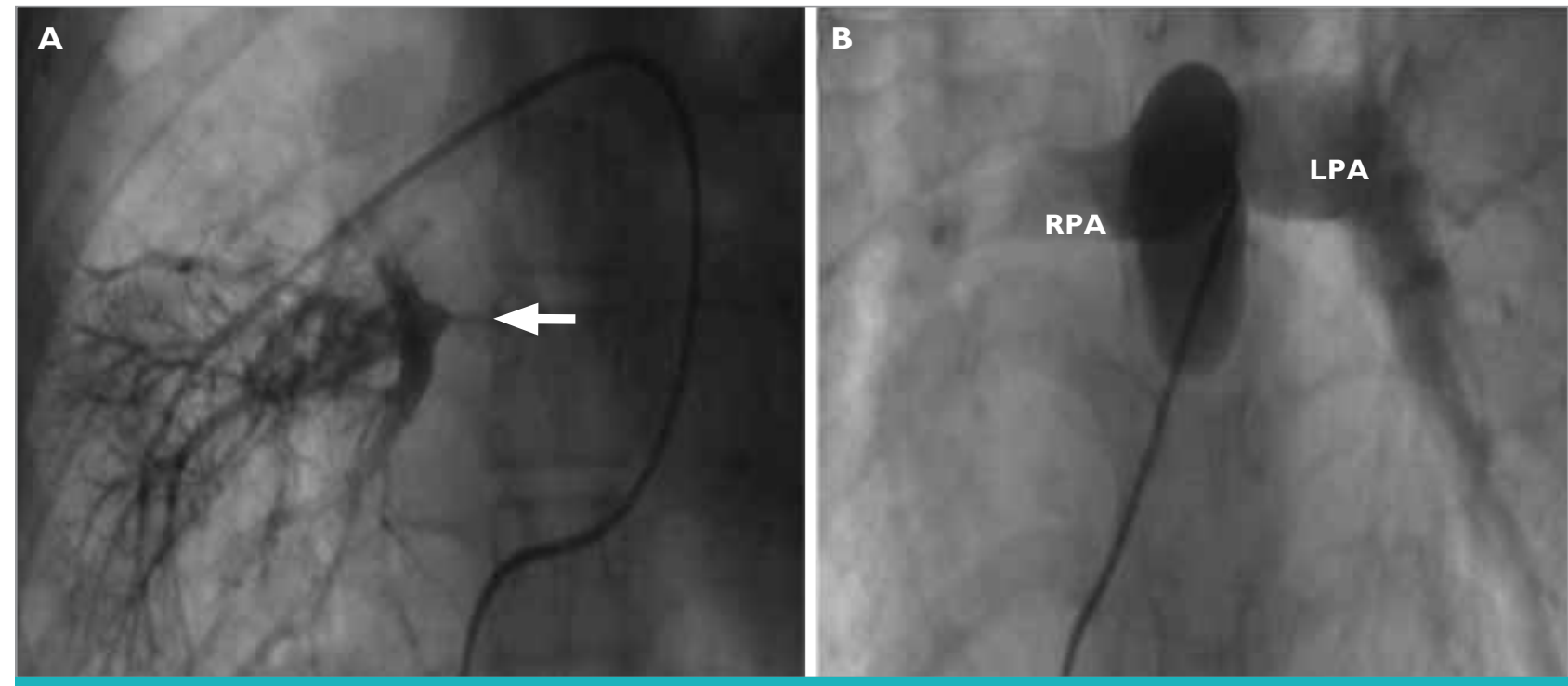

FIGURE 2A: The venous phase of a selective angiogram of the distal right pulmonary artery in Case 5 showing 2 pulmonary veins draining into a common vein, which has a discrete stenosis (arrow) at entry into the left atrium.

FIGURE 2B: Main pulmonary artery angiogram from case 5 showing a relatively small right pulmonary artery (RPA), as compared to left pulmonary artery (LPA).

$R P A=$ right pulmonary artery, $L P A=$ left pulmonary artery.

study, documented outcomes were poor. Only 2 patients underwent treatment for their PVS. One patient died from K. pneumoniae sepsis following a lobectomy on the side of the PVS for recurrent haemoptysis, while the other patient had PVS recurrence following surgical repair. One patient (case 5) has been followed up for 11 years since the diagnosis and at the age of 24 years continues to have recurrent episodes of minor haemoptysis and shortness of breath, and has refused further surgery.

Various treatment strategies, both surgical and transcatheter, have been employed in the treatment of pulmonary vein stenosis. Only 2 patients received interventions for their PVS in the study cohort - I of whom (case I) had a pulmonary vein widening with a pericardial patch. Conventional surgical strategies include endarterectomy (excision of the stenotic ring and direct anastomosis of the PV to LA endocardium) and pericardial patch venoplasty (resection of the stenotic tissue and patch anastomosis to enlarge the tightened segment).(1,9,10) A new surgical strategy called sutureless marsupialisation where the pericardium surrounding the affected $P V$ is directly attached to the LA, so direct stiches over the cut edges of the vessel are avoided, has been used. ${ }^{(9-11)}$ Pneumonectomy such as in case 2, may be necessary for patients with haemoptysis, while those with unrelenting progression and development of severe pulmonary hypertension, are managed with lung transplantation. ${ }^{(2,10)}$ Overall, surgical outcomes have been disappointing. The condition is generally unresponsive to treatment and tends to recur. ${ }^{(4,7,10)}$ Transcatheter interventions include the use of stents and balloon dilatation. ${ }^{(2,10,11)}$ There are, however, poor outcomes with these interventions and limited experience of percutaneous interventions in children. $(2,10,12)$ A recent study by Callahan, et al. explored the use of adjunct targeted biologic inhibition agents to treat paediatric PVS.(13) Histologic series have identified fibroblasts and myofibroblastlike cells as significant contributors to the mesenchymal proliferation that is a hallmark of pulmonary vein stenosis pathophysiology. (2.14) Callahan, et al. evaluated the use of imatinib mesylate with or without bevacizumab targeting neoproliferative myofibroblast-like cells with tyrosine kinase receptor expression, as adjuncts to modern interventional therapies for the treatment of multivessel intraluminal pulmonary vein stenosis. ${ }^{(13)}$ The results of the study were inconclusive with a major confounding factor being the use of other conventional management of the PVS during the study period. The role of these agents needs further evaluation.

\section{CONCLUSION}

This is first case series report of congenital PVS in an African setting. We have confirmed that congenital PVS is a rare condition and that all cases were associated with other 
congenital cardiac defects. Haemoptysis and respiratory signs are part of the presenting clinical spectrum, in keeping with the published literature. Our study patients presented late and may have had a less progressive disease. Variable increases in pulmonary artery pressures and markedly increased capillary wedge pressures were documented on the affected side. In view of the association with other CHD, we recommend that pulmonary vein interrogation be included in patients with CHD, particularly those presenting with haemoptysis, unilateral parenchymal lung changes and elevated pulmonary wedge pressures during routine imaging of the heart.

\section{Conflict of interest: none declared.}

\section{REFERENCES}

I. Heyneman LE, Nolan RL, Harrison JK, et al. Congenital unilateral pulmonary vein atresia radiological findings in three adult patients. AJR 2001;177:681685. https://www.ajronline.org/doi// 0.2214/ajr.177.3.1770681.

2. Latson LA, Prieto LR. Congenital and acquired pulmonary vein stenosis. Circulation 2007;115:103-108. https://www.ahajournals.org/doi//0.1/61/ CIRCULATIONAHA. 106.646166

3. Amin R, Kwon S, Moayedi Y, et al. Pulmonary vein stenosis: Case report and literature review. Can Respir J 2009; 16(6):e77-e80. https://www.ncbi.nlm.nih. gov/pubmed/2001 I721.

4. Driscoll DJ, Hesslein PS, Mullins CE. Congenital stenosis of individual pulmonary veins: Clinical spectrum and unsuccessful treatment by transvenous balloon dilatation. Am J Cardiol 1982;49:1767-1772. https://www. ncbi.nlm.nih.gov/pubmed/621 076

5. Reid JM, Jamieson MP, Cowan MD. Unilateral pulmonary vein stenosis. Br Heart J 1986;55:599-60I. https://www.ncbi.nlm.nih.gov/pmc/articles/ $\mathrm{PMCl} 236769$.

6. Kingston HM, Patel RG, Watson GH. Unilateral absence or extreme hypoplasia of pulmonary veins. Br Heart J 1983;49:1 48- I53. https://www. ncbi.nlm.nih.gov/pmc/articles/PMC48I277.

7. Holt DB, Moller JH, Larson S, et al. Primary pulmonary vein stenosis. Am J Cardiol 2007;99:568-572. https://www.ncbi.nlm.nih.gov/pubmed/I 7293205.

8. Breinholt JP, Hawkins JA, Minich L, et al. Pulmonary vein stenosis with normal connection: Associated cardiac abnormalities and variable outcome. Ann Thorac Surg 1999;68: I 64- I 68. https://www.ncbi.nlm.nih.gov/pubmed/ I 042 I I 34

9. Pazos-López P, García-Rodríguez C, Guitián-González A, et al. Pulmonary vein stenosis: Etiology, diagnosis and management. World J Cardiol 20 | 6;8(1):8 I-88. https://www.ncbi.nlm.nih.gov/pmc/articles/PMC4728109.

10. Shi G, Zhu Z, Chen H, et al. Surgical repair for primary pulmonary vein stenosis: Single-institution, midterm follow-up. J Thorac Cardiovasc Surg 20| 5; | 50: | 8 | - 88. https://www.ncbi.nlm.nih.gov/pubmed/25935589.

II. Pazos-López P, García-Rodríguez C, Guitián-González A, et al. Pulmonary vein stenosis: Etiology, diagnosis and management. World | Cardiol 2016 Jan;8(I):8I-88. https://www.ncbi.nlm.nih.gov/pmc/articles/PMC4728I09.

12. Bini RM, Cleveland DC, Ceballos R, et al. Congenital pulmonary vein stenosis. Am J Cardiol 1964;54:369-375. https://www.ncbi.nlm.nih.gov/ pubmed/64650। 8

13. Callahan R, Kieran MW, Baird CW, et al. Adjunct targeted biologic inhibition agents to treat aggressive multivessel intraluminal pediatric pulmonary vein stenosis. J Pediatr 2018;198:29-35. https://www.ncbi.nlm.nih.gov/ pubmed/29576325.

14. Kalfa D, Belli E, Bacha E, et al. Primary pulmonary vein stenosis: Outcomes, risk factors, and severity score in a multicentric study. Ann Thorac Surg 2017; 104: | 82-189. https://www.ncbi.nlm.nih.gov/pubmed/28633223. 